\title{
Review on Drought Tolerance in Plants Induced by Plant Growth Promoting Rhizobacteria
}

\author{
Zaffar Mahdi Dar ${ }^{1 *}$, Amjad Masood ${ }^{2}$, Arshad Hussain Mughal', \\ Malik Asif ${ }^{1}$ and Mushtaq Ahamd Malik ${ }^{1}$ \\ ${ }^{1}$ Division of Basic Sciences, ${ }^{2}$ Division of Agronomy, Faculty of Agriculture, \\ SKUAST- K Kashmir J\&K, India \\ *Corresponding author
}

\begin{tabular}{|l|}
\hline K e y w o r d s \\
Abiotic, Plant growth \\
promoting rhizobacteria, \\
Drought, Tolerance, \\
Hormones
\end{tabular}

\section{A B S T R A C T}

\section{Introduction}

Crop growth and development are constantly influenced by environmental stresses which are the most important yield reducing factors in the world (Dennis, 2000). Drought stress is considered as the most destructive abiotic stresses that increased in intensity over the past decades affecting world's food security. It may range from moderate and short to extremely severe and prolonged duration, restricting the crop yields (Bottner et al.,
Abiotic stresses are major constrains which adversely affect the plant growth and productivity. Among all abiotic stresses, drought is considered as one of the major constraints on agricultural productivity worldwide and is likely to further increase. Hence the need of the hour is to formulate the strategies that can minimize the loss in crop production under drought conditions. One of them being the exploitation of soil microbes which have the capacity to overcome the adverse effects of drought stress. In the current scenario, microbial role in plant adaptation towards drought stress is gaining more attention. In this regard plant growth promoting rhizobacteria (PGPR) can be employed to mitigate the drought adversities in the plants. This review deals with the mechanisms through which the PGPR minimize the harmful effects of drought stress in plants. In several studies it has been reported that these beneficial microorganisms colonize the plant (indole acetic acid) and ABA (absissic acid), enzymes like ACC (1-amino, cyclo propane 1-carboxylic acid) deaminase, promoting root growth and nutrient uptake, inducing accumulation of osmolytes and antioxidants. 
(Nair et al., 2008). Besides, the stomatal closure during drought conditions reduces the $\mathrm{CO}_{2}$ uptake by the plants, hence reducing the photosynthetic rate and plant yield.

Keeping in view the dangers posed by the drought stress and the increasing demand for food, a wide variety of efforts focusing on agro ecosystem and soil biological system as a whole is required to understand the stability of process. One of them being the exploitation of soil microbes which have the capacity to overcome the adverse affects of drought stress (Navnita et al., 2015). In the current scenario, microbial role in plant adaptation towards drought stress is gaining more attention. This strategy is not only easier but also cost effective. Millions of microbes inhabit plant root system forming a complex ecological community that influences plant growth and productivity through its metabolic activities and plant interactions (Schmidt et al., 2014).

The term PGPR was proposed by Kloepper et al., (1980) who defined it as a group of bacteria capable to actively colonize the plant root system and improve their growth and yield (Wu et al., 2005). A wide range of species belonging to the genus Pseudomonas, Azospirillum, Azotobacter, Klebsiella, Enterobacter, Alcaligenes, Arthrobacter, Burkholderia, Bacillus and Serratia were reported to have PGPR properties (Saharan and Nehra, 2011). PGPR represent about 2 to $5 \%$ of total rhizospheric bacteria (Antoun and Kloepper, 2001). They colonize all ecological niches of root to all stages of plant development, even in the presence of a competing microflora. The effects of PGPR depend on ecological and soil factors, plant species, plant age, development phase and soil type (Werner, 2001). For example, a bacterium which promotes plant growth through nitrogen fixation or phosphorus solubilization, certainly not produce beneficial effects to the plant when the soil receives chemical fertilizers. It has been reported in several studies that PGPR improves plant growth even under drought conditions through one or more mechanisms. Hence in the following sections, efforts have been made to appraise the role and underlying major mechanisms of PGPR in inducing tolerance to drought stress.

\section{Mechanism of PGPR mediated drought tolerance}

There are various strategies and mechanisms studied for enhancement of plant drought tolerance mediated by rhizobacteria but, the exact mechanism is still speculative. However, the literature suggests the involvement of the following possible mechanisms in promoting the drought tolerance by PGPR.

\section{Effect of PGPR on phytohormonal level}

Phytohormones such as indole acetic acid, gibberellins, ethylene, abscisic acid and cytokinins are produced by plants, which are important for their growth and development (Egamberdieva, 2013). Indole-3-acetic acid (IAA) is the best-characterized auxin produced by many plant associated bacteria, including PGPR (Spaepen et al., 2007a). PGPRs stimulate plant cell growth and division to become tolerant against environmental stresses mediated through biosynthesis of phytohormones (Glick and Pasternak, 2003). Various plant species inoculated with IAA producing bacteria increased root growth and/or enhanced formation of lateral roots and roots hairs (Dimkpa et al., 2009) thus increasing water and nutrient uptake (Mantelin and Touraine, 2004), helping plants to cope with water deficit (Egamberdieva and Kucharova, 2009). Bacterial treatment in wheat (Arzanesh et al., 2011) induced decrease in leaf water potential and increase in leaf water content, which was 
attributed to the production of plant hormones such as IAA by the bacteria that enhanced root growth and formation of lateral roots their by increasing uptake of water and nutrients under drought stress resulting in better grain yield and higher mineral quality as compared to untreated plants. Similarly, inoculation with $A$. brasilense $\mathrm{Cd}$ and $B$. thuringiensis in common bean (German et al., 2000) and Lavandula dentate plants (Armada et al., 2014) respectively increased root projection area, specific root length and specific root area, nutritional physiology and metabolic activities of plant. A. brasilense produces nitric oxide, a small diffusible gas which acts as a signaling molecule in IAA inducing pathway and helps in adventitious root development in tomato plants (Molina Favero et al., 2008).

Cellular dehydration induced biosynthesis of ABA, a stress hormone during water deficit condition (Kaushal and Wani, 2015). In addition to IAA, production of ABA by Azospirillum lipoferum alleviated drought stress in maize plants (Cohen et al., 2009). ABA is involved in water loss regulation by controlling stomatal closure and stress signal transduction pathways (Yamaguchi-Shinozaki and Shinozaki, 1994). Arabidopsis plants inoculated with $A$. brasilense had elevated levels of ABA compared to non-inoculated plants. PGPR Phyllobacterium brassicacearum isolated from the rhizosphere of Brassica napus enhanced osmotic stress tolerance in inoculated Arabidopsis plants by elevating ABA content, leading to decreased leaf transpiration conferring drought stress resistance (Bresson et al., 2013).

\section{Effect of PGPR on plant root system}

Many PGPR are able to produce phytohormones among which IAA is the bestcharacterized auxin produced by many plant associated bacteria, including PGPR (Spaepen et al., 2007a). Exogenous IAA controls a wide variety of processes in plant development and plant growth: low concentrations of IAA can stimulate primary root elongation, whereas high IAA levels stimulate the formation of lateral roots, decrease primary root length and increase root hair formation (Remans et al., 2008). IAA is usually synthesized by rhizobacteria from tryptophan, which is found at different concentrations in root exudates according to plant genotype (Kamilova et al., 2006). In PGPR strains, several IAA biosynthetic pathways have been described depending on the metabolic intermediates (Spaepen et al., 2007a).

It has also been reported that certain PGPR produce some secondary metabolites such as 2,4-diacetylphloroglucinol (DAPG), and nitric oxide (NO). Several PGPR strains like Azospirillum brasilense have nitrite reductase activity and consequently are able to produce NO during root colonization (Pothier et al., 2007). NO is involved in the auxin signaling pathway controlling lateral root formation (Molina-Favero et al., 2008). DAPG is a wellknown antimicrobial compound produced by pseudomonads (Couillerot et al., 2009). At lower concentrations, DAPG can also be a signal molecule for plants, inducing systemic resistance (Bakker et al., 2007), stimulating root exudation (Phillips et al., 2004), and enhancing root branching (Walker et al., 2011). DAPG can interfere with an auxin dependent signaling pathway (Brazelton et al., 2008). Indeed, applications of exogenous DAPG, at a concentration around $10 \mu \mathrm{M}$, inhibited primary root growth and stimulated lateral root production in tomato seedlings.

PGPR has been found to modify the chemical composition of root cell walls that directly promote plant growth. El Zemrany et al., (2007) concluded that roots inoculated with Azospirillum lipoferum had lower lignin 
content than uninoculated ones facilitating cell elongation by rapid water uptake, and therefore overall root elongation. Similarly, Azospirillum irakense produces pectate lyases that are capable of degrading the pectate content of root cell wall and might allow its progression between root cortex cells and its functioning as an endophyte (Bekri et al., 1999).

Modifications of root cell wall ultrastructure are thought to result mainly from PGPR triggered changes in plant gene expression. Indeed, Bacillus subtilis GB03 promotes Arabidopsis growth by producing volatile organic compounds that were shown to modulate the expression of 38 genes with known functions associated with cell wall structure (Zhang et al., 2007). Among them, 30 were implicated in cell wall expansion or loosening. The endophytic PGPR Azospirillum irakense was also shown to stimulate the expression of polygalacturonase genes in inoculated rice roots (Sekar et al., 2000).

\section{Effect of PGPR on ACC deaminase activity}

Under biotic and abiotic stresses plant drought tolerance is regulated by ethylene level (Hardoim et al., 2008). In the biosynthetic pathway of ethylene, Sadenosylmethionine (S-AdoMet) is converted by 1-aminocyclopropane-1-carboxylate synthase (ACS) to 1-aminocyclopropane-1carboxylate (ACC), the immediate precursor of ethylene. Under stress conditions, the plant hormone ethylene endogenously regulates plant homoeostasis resulting in reduced root and shoot growth. It has been reported that ACC deaminase producing PGPR Achromobacter piechaudii ARV8 significantly increased the fresh and dry weights of both tomato and pepper seedlings and reduced the ethylene production under drought stress (Mayak, 2004). ACC deaminase producing bacteria Pseudomonas fluorescens biotype $\mathrm{G}$ (ACC-5) eliminated the effects of drought stress on growth, yield, and ripening of pea in both pot and field trials (Arshad et al., 2008). In addition to it the bacteria induced longer roots, which led to an increased uptake of water from soil under drought stress (Zahir et al., 2008) which resulted in more seed yield, seed number and seed nitrogen accumulation and restoring nodulation which was depressed in drought stress conditions (Dodd et al., 2005). Rhizobacteria populating the sites where water is limited with repeated dry periods are likely to be more stress adapting and pro-mote plant growth than those bacteria isolated from the sites where water sources are abundant (Mayak, 2004).

Actually, PGPR are more widely able to lower plant ethylene levels through deamination of 1-aminocyclopropane-1carboxylic acid (ACC). Many genomes of PGPR do contain a gene (acdS) coding for an ACC deaminase, which degrades ACC into ammonium and $\alpha$-ketobutyrate (Prigent Combaret et al., 2008). By lowering the abundance of the ethylene precursor ACC, the PGPR AcdS activity is thought to decrease root ethylene production, which can in turn alleviate the repressing effect of ethylene on root growth (Glick, 2005). Plant ACC is sequestered and degraded by ACC deaminase producing bacteria to supply nitrogen and energy.

\section{Impact of PGPR on plant nutrition}

Plant growth-promoting rhizobacteria can directly increase nutrient supply in the rhizosphere and stimulate ion transport systems in root. With regards to increased nutrient supply, two main types of bacterial activities can be considered. Firstly, phosphate solubilization is one key effect of PGPR on plant nutrition. Soils generally contain a large amount of phosphorus, which accumulates in the wake of regular fertilizer 
applications, but only a small proportion of the latter is available for plants. Plants are able to absorb on their own the mono and dibasic phosphate; however, organic or insoluble forms of phosphate need to be mineralized or solubilized by microorganisms (Ramaekers et al., 2010). Many PGPR such as Pseudomonas, Bacillus, Rhizobium are able to dissolve insoluble forms of phosphate (Richardson et al., 2009) through two of the main processes: acidification of the external medium through the release of low molecular weight organic acids such as gluconic acid that chelates the cations bound to phosphate (Miller et al., 2009), and production of phosphatases/phytases that hydrolyse organic forms of phosphate compounds. Capsicum plants inoculated with PGPR had a $\mathrm{P}$ and $\mathrm{K}$ uptake $40 \%$ higher than that on uninoculated. In addition to $\mathrm{N}$ and $\mathrm{P}$ PGPR application in tomato has been found to improve iron and zinc uptake. Secondly, many associated bacteria can fix $\mathrm{N}_{2}$ so that they could provide nitrogen to the plant. Evidence in favor of the participation of PGPR to the plant $\mathrm{N}$ budget has been reported for several plants, especially sugarcane (Boddey et al., 2003).

It is commonly hypothesized that nutrient uptake is increased as a consequence of increased root surface area triggered by PGPR. However, root ion transporters are under the control of regulatory processes that adjust their activity to the plant nutritional demand (Nazoa et al., 2003), so that regulations of root development and ion transporter activities are antagonistically coordinated to maintain steady nutrient acquisition rate (Touraine, 2004).

\section{Impact of PGPR on osmoregulation}

Plant adaptation to drought stress is associated with metabolic adjustments that lead to the accumulation of several compatible solute like proline, sugars, polyamines, betaines, quaternary ammonium compounds, polyhydric alcohols and other amino acids and water stress proteins like dehydrins (Close, 1996). These small, uncharged, soluble molecules, which include proline, glycine betaine, polyamines, and melatonin, do not affect cellular function directly. These solutes decrease the hydric potential of cells by trapping water molecules or by retaining the water molecules they are already associated with which is termed as osmoregulation and the accumulated solutes are called as compatible solutes because their accumulation in the plant cell does not have any harmful effect on the cell physiology. Compatible solutes can increase the stability and integrity of membranes and proteins, preventing or lessening cellular damage. It has been reported in several studies that PGPR secrete osmolytes in response to drought stress, which act synergistically with plant produced osmolytes and stimulate plant growth (Paul et al., 2008). PGPR Pseudomonas putida GAP-P45 inoculation improved plant biomass, relative water content and leaf water potential by accumulation of proline in maize plants exposed to drought stress (Sandhya et al., 2010) hence adding to its existing concentrations (Ansary et al., 2012).

Drought tolerance of $L$. dentate showed that PGPR B. thuringiensis (Bt) inoculation enhanced shoot proline accumulation under drought stress (Armada et al., 2014). Similarly, tomato treated with phosphate solubilizing bacteria (PSB) (Bacillus polymyxa) secreted excess proline to cope up with the drought condition (Shintu and Jayaram, 2015). PGPR consortia containing Pseudomonas jessenii R62, Pseudomonas synxantha R81 and Arthrobacter nitroguajacolicus strain YB3, strain YB5 enhanced plant growth in both drought tolerant and drought sensitive cultivars of rice. PGPR inoculation increases proline content in plants due to up regulation of its biosynthesis pathway hence maintaining cell 
water status and protects the cell membranes and proteins from the injury caused by drought stress (Sandhya et al., 2010).

\section{Impact of PGPR on plant antioxidative system}

Studies have shown that water deficit is a major environmental factor limiting the productivity of plants and may cause damage to plant tissues, especially roots, through the formation of reactive oxygen species (ROS) such as $\mathrm{H}_{2} \mathrm{O}_{2}, \mathrm{O}_{2}^{-}$and $\mathrm{OH}^{-}$, due to high susceptibility of root meristem activity to ROS. ROS are toxic molecules capable of causing oxidative damage to the lipids, DNA and proteins (Miller et al., 2010). If these molecules are not managed properly, they cause significant damage to the membranes and cause catastrophic effects on cell metabolism. Therefore, efficient quenching of ROS is very crucial for survival and cell metabolism under stress conditions. Oxidative stress occurs when the antioxidant defence system is overloaded and is unable to maintain an adequate cellular redox balance. The antioxidant system includes both enzymatic (e.g., superoxide dismutases, ascorbate peroxidases, and catalases) and non-enzymatic molecules (e.g., glutathione, flavonoids, carotenoids, and tocopherols) (Mittler, 2002).

In order to decrease the deleterious effects of ROS, antioxidant promoting systems are required, such as PGPR application. Basil plants (Ocimum basilicum L.) treated with Pseudomonas sp. under drought stress significantly increased the catalase enzyme activity, similarly when treated with microbial consortia containing Pseudomonades sp., Bacillus lentus and A. brasilense highest activity of glutathione peroxidase and ascorbate peroxidase was observed (Heidari and Golpayegani, 2011). PGPRs, P. jessenii R62, $P$. synxantha $\mathrm{R} 81$ and $A$. nitroguajacolicus strain YB3 and strain YB5 used as consortia's enhanced plant growth and induction of stress related enzymes superoxide dismutase, catalase (CAT), peroxidise (PX), ascorbate peroxidise (APX) and lower level of $\mathrm{H}_{2} \mathrm{O}_{2}$, malondialdehyde (MDA) in Sahbhagi (drought tolerance) and IR-64 (drought sensitive) cultivars of rice under drought stress compared to control (Gusain et al., 2015). Maize plants inoculated with five drought tolerant plant growth promoting Pseudomonas spp. strains namely $P$. entomophila, $P$. stutzeri, $P$. putida, $P$. syringae, and $P$. montelli subjected to drought stress showed significantly lower activity of antioxidant enzymes as compared to uninoculated plants (Sandhya et al., 2010). In another experiment on maize plants it was found that plants inoculated with Bacillus species developed protection against drought stress by reducing activity of the antioxidant enzymes APX and Glutathione peroxidase (GPX) (Vardharajula et al., 2011). Effectiveness of autochthonous PGPR $B$. thuringiensis (Bt) in Lavandula dentata and Salvia officinalis under drought conditions promoted growth and drought avoidance by decrease of glutathione reductase (GR) and ascorbate peroxidase (APX) activity (Armada et al., 2014). The reduction in the antioxidant activity by inoculation with PGPR is related to less generation of free radicals hence reducing the antioxidant activity. These studies provide evidence for beneficial effect of PGPRs application in enhancing drought tolerance of plants by altering the antioxidants activity and reduction in active oxygen species under water deficit conditions (Gusain et al., 2015).

It is quite clear from the above discussion that PGPR mediates plant drought tolerance by overcoming the deleterious effects posed by drought stress through changes in hormonal level like IAA and ethylene which in turn promote root elongation as well as its 
architecture favorable for the increased water uptake which is additionally being favored by enhancement in the accumulation of solutes in the plant cell that prevents the loss of water from the cell. The danger posed by the free radical to the plant through different means is prevented by PGPR through enhancement in the level of different antioxidants followed by the reduction in the ROS hence preventing the cell death.

\section{References}

Ansary, M.H., Rahmani, H.A., Ardakani, M.R., Paknejad, F. D., Habibi, S. and Mafakheri. 2012. Effect of Pseudomonas fluorescens on proline and phytohormonal status of maize ( $\mathrm{Zea}$ mays L.) under water deficit stress. Annals of Biological Research. 3: 10541062.

Antoun, H. and Kloepper, J. W. 2001. Plant growth promoting rhizobacteria. In. Encyclopedia of Genetics, ed. Brenner S., Miller J. H., New York: USA. pp. 1477-1480.

Armada, E., Roldan, A. and Azcon, R. 2014. Differential activity of autochthonous bacteria in controlling drought stress in native Lavandula and Salvia plants species under drought conditions in natural arid soil. Microbiology and Ecology. 67: 410-420.

Arshad, M., Sharoona, B. and Mahmood, T. 2008. Inoculation with Pseudomonas spp. containing ACC deaminase partially eliminates the effects of drought stress on growth, yield and ripening of pea ( $P$. sativum L.). Pedosphere. 18: 611-620.

Arzanesh, M.H. Alikhani, H.A., Khavazi, K., Rahimian, H.A. and Miransari, M. 2011. Wheat (Triticum aestivum L.) growth enhancement by Azospirillum sp. under drought stress. World Journal of Microbiology and Biotechnology. 27: 197-205

Bakker, P. A., Pieterse, C. M. and Loon, L. C. 2007. Induced systemic resistance by fluorescent Pseudomonas spp. Phytopathology. 97: 239-243.

Bekri, M. A., Desair, J., Keijers, V., Proost, P., Searle-van Leeuwen M. and Vanderleyden, J., (1999). Azospirillum irakense produces a novel type of pectate lyase. Journal of Bacteriology. 181: 2440-2447.

Boddey, R. M., Urquiaga, S., Alves, B. J. R. and Reis, V. 2003. Endophytic nitrogen fixation in sugarcane: present knowledge and future applications. Plant Soil. 252: 139-149.

Bottner, P., Couteaux, M.M. and Vallejo, V.R. 1995. Soil organic matter in Mediterranean-type ecosystems and global climatic changes: a case studythe soils of the Mediterranean basin. Global Change and Mediterranean Type Ecosystems. 306-325

Brazelton, J. N., Pfeufer, E. E., Sweat, T. A., Mcspadden Gardener, B. B. and Coenen, C. 2008.2 2,4diacetylphloroglucinol alters plant root development. Molecular Plant Microbe. Interactions. 21: 1349-1358.

Bresson, J., Varoquaux, F., Bontpart, T., Touraine, B. and Vile, D. 2013. P.G.P.R. Thestrain Phyllobacterium brassicacearum STM196 induces a reproductive delay and physiological changes that result in improved drought tolerance in Arabidopsis. New Phytology. 200: 558-569.

Close, T. J. 1996. Dehydrins emergence of a biochemical role of a family of plant dehydration proteins. Physiologia Plantarum. 97: 795-803.

Cohen, A.C., Travaglia, C.N., Bottini, R. and Piccoli P.N. 2009. Participation of abscisic acid and gibberellins produced by endophytic Azospirillum in the 
alleviation of drought effects in maize. Botanique. 455-462.

Couillerot, O., Prigent-Combaret, C., Caballero-Mellado, J., Menne-Loccoz, Y. 2009. Pseudomonas fluorescens and closely related fluorescent pseudomonads as biocontrol agents of soil borne phytopathogens. Letters of Applied Microbiology. 48: 505-512.

Dennis, B. E. and Bruening, W. P. 2000. Potential of early maturing soybean cultivars in late plantings. Agronomy Journal. 92:532 -537.

Dimkpa, C., Weinand, T., Asch, F. 2009. Plant rhizobacteria interactions alleviate abiotic stress conditions. Plant Cell Environment. 32: 1682-1694.

Dodd, A.A., Belimov, W.Y., Sobeih, V.I., Safronova, D., Grierson, Davies, W. J. 2005. Will modifying plant ethylene status improve plant productivity in water-limited environments? 4th International Crop Science Congress.

Egamberdieva, D. 2013. The role of phytohormone producing bacteria in alleviating salt stress in crop plants. In: Miransari M., editor. Biotechnological techniques of stress tolerance in plants. Stadium Press; USA: 21-39.

Egamberdieva, D. and Kucharova, Z. 2009. Selection for root colonizing bacteria stimulating wheat growth in saline soils. Biology and Fertility of Soils. 45: 561573

El Zemrany, H., Czarnes, S., Hallett, P. D., Alamercery, S., Bally, R. and JocteurMonrozier, L. (2007). Early changes in root characteristics of maize (Zea mays) following seed inoculation with the PGPR Azospirillum lipoferum CRT1. Plant Soil. 291: 109-118.

German, M.A., Burdman, S., Okon, Y. and Kigel, J. 2000. Effects of Azospirillum brasilense on root morphology of common bean (Phaseolus vulgaris L.) under different water regimes. Biology and Fertility of Soils. 32: 259-264.

Glick, B. R. 2005. Modulation of plant ethylene levels by the bacterial enzyme ACC deaminase. FEMS Microbiology Letters. 251(1):1-7

Glick, B.R. and Pasternak, J. J. 2003. Molecular Biotechnology: Principles and Application Recombinant Dna Technology (3rd ed.), ASM Press, Washington.

Gusain, Y.S., Singh, U.S. and Sharma, A.K. 2015. Bacterial mediated amelioration of drought stress in drought tolerant and susceptible cultivars of rice (Oryza sativa L.). African Journal of Biotechnology. 14: 764-773.

Hardoim, P.R., Van Overbeek, L.S. and Elass, J. D. 2008. Properties of bacterial endophytes and their proposed role in plant growth. Trends in Microbiology. 16(10):463-71.

Heidari, M. and Golpayegani, A. 2011. Effects of water stress and inoculation with plant growth promoting rhizobacteria (PGPR) on antioxidant status and photosynthetic pigments in basil (Ocimum basilicum L.). Journal of Saudi Society of Agriculture Sciences. 11: 57-61.

Jose, M. and Oechel, W.C. 1995. Global Change and Mediterranean-type Ecosystems. Ecological studies. 306325

Kamilova, F., Kravchenko, L. V., Shaposhnikov, A. I., Azarova, T., Makarova, N., Lugtenberg B. 2006. Organic acids, sugars and Ltryptophane in exudates of vegetables growing on stonewool and their effects on activities of rhizosphere bacteria. Molecular Plant Microbe Interactions. 9: 250-256.

Kaushal, M. and S.P. Wani. 2015. Plantgrowth-promoting rhizobacteria: drought stress alleviators to ameliorate 
crop production in dry lands. Annals of Microbiology. 66(1): 1-8.

Kloepper, J. W., Leong, J., Teintze, M. and Schroth M. N. 1980. Enhanced plant growth by siderophores produced by plant growth promoting rhizobacteria. Nature. 286:885-886.

Mayak, S. 2004. Plant growth promoting bacteria that confer resistant to water stress in tomato and pepper. Plant science. 166(2): 525-530.

Miller, G., Susuki, N., Ciftci-Yilmaz, and Mittler, S., R. 2010. Reactive oxygen species homeostasis and signalling during drought and salinity stresses. Plant Cell Environment. 33: 453-467.

Miller, S. H., Browne, P., Prigent-Combaret, C., Combes-Meynet, E., Morrissey, J. P and O'Gara, F. 2009. Biochemical and genomic comparison of inorganic phosphate solubilisation in Pseudomonas species. Environmental Microbiology Reports. 2: 403-411.

Mittler, R. 2002. Oxidative stress, antioxidants and stress tolerance. Trends in Plant Sciences. 7: 405-410.

Molina-Favero, C., Creus, C. M., Simontacchi, M., Puntarulo, S., Lamattina, L. 2008. Aerobic nitric oxide production by Azospirillum brasilense Sp245 and its influence on root architecture in tomato. Molecular Plant Microbe Interactions. 21: 1001-1009.

Nair, A., Abraham, T.K. and Jaya, D.S. 2008. Studies on the changes in lipid peroxidation and antioxidants in drought stress induced Cowpea (Vigna unguiculata L.) varieties. Journal of Environmental Biology. 29: 689-691.

Navnita, S., Kuldeep, Y., Jagbeer C., Neetu, B. and Ashok A. 2015. Arbuscular Mycorrhizal Symbiosis and Water Stress: A Critical Review. Pertanika Journal of Tropical Agricultural Sciences. 38(4): $427-453$.
Nazoa, P., Vidmar, J. J., Tranbarger, T. J., Mouline, K., Damiani, I. and Tillard, P., (2003). Regulation of the nitrate transporter gene AtNRT2.1 in Arabidopsis thaliana: responses to nitrate, amino acids and developmental stage. Plant Molecular Biology. 52: 689-703.

Paul, L.F., Primavesi, D., Jhurreea, Y. and Zhang. 2008. Trehalose metabolism and signaling. Annual Review of Plant Biology. 59: 417-441.

Phillips, D. A., Fox, T. C., King, M. D., Bhuvaneswari, T. V., and Teuber, L. R. 2004. Microbial products trigger amino acid exudation from plant roots. Plant Physiology. 136: 2887-2894.

Pothier, J. F., Wisniewski-Dyé, F., WeissGayet, M., Mënne-Loccoz, Y., PrigentCombaret, C. (2007). Promoter-trap identification of wheat seed extractinduced genes in the plant-growthpromoting rhizobacterium Azospirillum brasilense Sp245. Microbiology. 153: 3608-3622.

Prigent-Combaret, C., Blaha, D., Pothier, J. F., Vial, L., Poirier, M. A. and Wisniewski-Dyé, F. 2008. Physical organization and phylogenetic analysis of $a c d R$ as leucine-responsive regulator of the 1-aminocyclopropane-1carboxylate deaminase gene acdS in phytobeneficial Azospirillum lipoferum 4B and other proteobacteria. FEMS Microbiology and Ecology. 65: 202219.

Rahdari, P. and Hoseini, S.M., 2012. Drought stress, a review. International Journal of Agronomy and Plant Production. 3:443-446.

Ramaekers, L., Remans, R., Rao, I. M., Blair, M. W. and Vanderleyden, J. 2010. Strategies for improving phosphorus acquisition efficiency of crop plants. Field Crops Research. 117: 169-176. 
Remans, R., Beebe, S., Blair, M., Manrique,G. Tovar, Tovar, E., Rao, I., Croonenborghs, A. Torres-Gutierrez, R., El-Howeity, M. Michiels, J. and Vanderleyden, J. 2008. Physiological and genetic analysis of root responsiveness to auxin-producing plant growth-promoting bacteria in common bean (Phaseolus vulgaris L.). Plant Soil. 302: 149-161.

Richardson, A. E., Baréa, J. M., McNeill, A. M. and Prigent-Combaret, C. 2009. Acquisition of phosphorus and nitrogen in the rhizosphere and plant growth promotion by microorganisms. Plant Soil. 321: 305-339.

Saharan, B. S. and Nehra, V. 2011. Assessment of Plant growth promoting attributes of cotton (Gossypium hirsutum) rhizosphere isolates and their potential as bio-inoculants. Journal of Environmental Research and Development. 5(3): 575-583.

Sandhya, S. K. Z., Ali, M., Grover, G., Reddy, B. and Venkateswaralu. 2010. Effect of plant growth promoting Pseudomonas spp. on compatible solutes antioxidant status and plant growth of maize under drought stress. Plant Growth Regulation, 62: 21-30.

Schmidt, R., Martina, K., Amr, M, Elshahat, M. R., Marlene, M., Kenneth, B. J., Rudolf, B. and Gabriele, B. 2014. Effects of bacterial inoculants on the indigenous microbiome and secondary metabolites of chamomile plants. Frontiers in Microbiology. 5: 64.

Sekar, C., Prasad, N. N. and Sundaram, M. D. 2000. Enhancement of polygalacturonase activity during auxin induced para nodulation and endorhizosphere colonization of Azospirillum in rice roots. Indian Journal of Experimental Biology. 38: 80-83.
Selvakumar, G., Reetha, S. and Thamizhiniyan, P. 2012. Response of biofertilizers on growth, yield attributes and associated protein profiling changes of blackgram (Vigna mungo L. Hepper). World Applied Sciences Journal. 16(10): 1368-1374.

Shintu, P.V. and Jayaram, K.M. 2015. Phosphate solubilising bacteria (Bacillus polymyxa)-An effective approach to mitigate drought in tomato (Lycopersicon esculentum Mill). Tropical Plant Research. 2: 17-22.

Spaepen, S., Vanderleyden, J. and Remans, R. 2007. Indole- 3-acetic acid in microbial and microorganism-plant signaling. FEMS Microbiology Reviews. 31: 425448.

Touraine, B. 2004. "Nitrate uptake by rootstransporters and root development," in Nitrogen Acquisition and Assimilation in Higher Plants eds De Kok L. J., Stulen I., editors. Dordrecht: Kluwer Academic Publishers. 1-34

Vardharajula, S., Zulfikar Ali, S., Grover, M., Reddy, G., and Bandi, V. 2011. Drought-tolerant plant growth promoting Bacillus spp., effect on growth, osmolytes, and antioxidant status of maize under drought stress. Journal of Plant Interactions. 6: 1-14.

Walker, V., Bertrand, C., Bellvert, F., MenneLoccoz, Y., Bally, R. and Comte, G. 2011. Host plant secondary metabolite profiling shows a complex, straindependent response of maize to plant growth-promoting rhizobacteria of the genus Azospirillum. New Phytology. 189: 494-506

Werner, T., Motyka, V., Strnad, M. and Schmülling, T. 2001. Regulation of plant growth by cytokinin. Proceedings of the National Academy of Sciences, USA 98, 10487-10492.

Wu, Q.S., Xia, R.X. and Zou, Y.N. 2008. Improved soil structure and citrus 
growth after inoculation with three arbuscular mycorrhizal fungi under drought stress. European Journal of Soil Biology. 44: 122-128.

Yamaguchi Shinozaki, K. and Shinozaki, K. 1994. A novel cis-acting element in an Arabidopsis gene is involved in responsiveness to drought, lowtemperature, or high-salt stress. Plant Cell. 6: 251-264.

Zahir, Z.A., Munir, A., Asghar, H.N., Shahroona, B. and Arshad, M. 2008. Effectiveness of rhizobacteria containing ACC-deaminase for growth promotion of peas ( $P$. sativum) under drought conditions. Journal of
Microbiology and Biotechnology. 18: 958-963.

Zhang, H., Kim, M. S., Krishnamachari, V., Payton, P., Sun, Y. and Grimson, M. (2007). Rhizobacterial volatile emissions regulate auxin homeostasis and cell expansion in Arabidopsis. Planta. 226: 839-851.

Zhu, J., X. Fu, Y.D. Koo, and J. K. Zhu. 2007. An enhancer mutant of Arabidopsis salt overly sensitive 3 mediates both ion homeostasis and the oxidative stress response. Molecular and Cell Biology. 27:5214-5224

\section{How to cite this article:}

Zaffar Mahdi Dar, Amjad Masood, Arshad Hussain Mughal, Malik Asif and Mushtaq Ahamd Malik. 2018. Review on Drought Tolerance in Plants Induced by Plant Growth Promoting Rhizobacteria. Int.J.Curr.Microbiol.App.Sci. 7(05): 412-422. doi: https://doi.org/10.20546/ijcmas.2018.705.053 